ด

columns have to be repeated at the MHRT. Any discovery by the medical member that is not in the reports can be reported, either by the President or the medical member, as the MHRT starts. Alternatively, the medical member may elicit the information by asking questions of the appropriate 'witnesses' before him/her and not by giving it himself/herself as evidence. Medical members need not themselves give evidence.

(g) The patient's representative will have seen the patient before the hearing and increasingly often has gained access to the case notes, thus further diminishing the likelihood of information being concealed. Furthermore, he or she can call for his or her own independent psychiatric assessment, although, since the revision of legal aid regulations, these seem to be sought much less frequently.

In Rooth's view the medical member's "insider perspective is irreplaceable". I would prefer 'integrated' to 'insider', but agree with him wholeheartedly, for the reasons given above, that it is 'irreplaceable'.

DEPARTMENT OF HEALTH (2000) Reforming the Mental Health Act. Part I: The New Legal Framework. London: The Stationery Office.

G. E. Langley Medical Member, MHRT, Consultant Psychiatrist (Retired)

\section{Patient or client?}

Sir: The use of terms for those who experience mental health difficulties is contentious and political. It is also above all dependent on context. I am not at all surprised that Ritchie et al (Psychiatric Bulletin, December 2000, 24, 447-450) found the term 'patient' was preferred by out-patient attendees, I regularly use the term patient without complaint for those who are currently receiving treatment.

However, there needs to be a term for those who have received such treatment in the past and who have a legitimate interest in the workings of the mental health services. 'Patient' is not an appropriate term to identify, for example, someone sitting on a planning committee who is there by virtue of having a personal experience of mental illness. We need a term for this and most people in this category accept the term 'service user'.

Some people prefer to be called 'survivors' and when you listen to their experiences of mental health services this can seem quite appropriate. I would suggest asking people how they identify themselves and then showing them the courtesy of using their preferred term. The suggestion from Hodgkiss (Psychiatric Bulletin, December 2000, 24, 441) that user involvement and empowerment might be derailed by a name change is like expecting a juggernaut to be stopped by a pea. Service user involvement is here to stay. There is a lot of energy in the user/ survivor movement (see, for example http://www.madpride.net).

We should be working with 'service users' in order to improve services for our patients'; some of whom may be the same people in a different context.

Alison J Gray Senior Registrar, West Midlands Rotation, St Anne's Orchard, Worcester Road, LinkTop, Malvern, WorcestershireWR14 2EZ; e-mail: ajgpsych@yahoo.co.uk.

Sir: It is with interest that we noted your publication of Ritchie et al's study 'Patient or client? The opinions of people attending a psychiatric clinic' (Psychiatric Bulletin, December 2000, 24, 447-450). As a community adolescent mental health team we wondered about the best way to address the people who were attending the unit. Between February 2000 and May 2000 we conducted a small survey and wrote to 133 people who had accessed the service and in response we received 42 replies. There were a number of questions on the survey, but in answer to the question about the preferred terminology to describe a patient/client the responses were as follows:

$\begin{array}{lr}\text { Servxice user } & 3 \\ \text { Patient } & 15 \\ \text { Customer } & 1 \\ \text { Client } & 16 \\ \text { Other } & 7\end{array}$

The preference was slightly in favour of the term 'client' as opposed to 'patient', with very little preference for service user or customer. It may be significant that our survey was only of clients between the ages of 16 and 19 years, whereas in the Ritchie et al's study the mean age was between 35 and 39 years. This might indicate a shift, which is influenced by age and points to an emerging change in culture. Perhaps the most significant finding was that only 42 clients out of 133 were sufficiently exercised by questions of this sort to return the questionnaire in its postage paid envelope. This question may be of more interest to professionals than clients.

Joe McDonald Consultant Adolescent Psychiatrist, Tony Ross CommunityAdolescent Psychiatric Nurse, Estelle Eaton Social Worker, The Barnes Unit, Durham Road, Sunderland, SR3 4AF; e-mail: joe@adolescentpsychiatry.co.uk

Sir: The article by Ritchie et al (Psychiatric Bulletin, December 2000, 24, 447-450) provides a useful contribution to the debate about the use of titles. I agree that the term 'patient' is appropriate for someone who attends a psychiatric outpatient clinic. However, mental health care is diverse and consists of services provided by numerous agencies. What title should we give the 'patient' who, after attending the clinic then visits a day centre run by a voluntary organisation? This service may be essential for his or her mental health, but surely he or she is not a patient of the centre's manager. Similarly, the 'patient' may need home visits from social services but I doubt whether social workers would regard the person as their 'patient'. Further confusion occurs when we consider people who have been diagnosed with a mental health problem but who are well and not in contact with any services. Ritchie et al's study was context specific and in their context the term 'patient' seems fine. In other contexts 'client' or 'service user' may also be suitable. I see two solutions to this problem. One is an acceptance that one person can have different titles at the same time, each of which represent the relationship that he or she has with the service provider. The other is to use a general title that applies to all situations. How about 'individual' or 'person'?

Paul McCrone Senior Lecturer in Health Economics, Health Services Research Department, Institute of Psychiatry, De Crespigny Park, London SE5 8AF

\section{St John's wort and ecstasy use}

Sir: I learnt from a patient who misuses illegal drugs that St John's wort has become a popular way of avoiding depressive mood swings following heavy ecstasy use. I wonder if this is a practice that is widespread around the country, or merely confined to the Yorkshire region.

G. E. P.Vincenti Consultant Psychiatrist

\section{The limited value of the annual physical health examination in long-term secure care}

Sir: We were concerned that psychiatric patients have increased physical morbidity and mortality (Santhouse \& Holloway, 1999), yet their general health care may be neglected. Prisoners also end up with reduced access to health care (Smith 1999). Thus, we wondered how effective the annual physical examination is for our long-stay psychiatric patients at Rampton high security hospital. We felt this was particularly needed as general practice services have extended in recent years.

An SPSS computer program (weighted to ensure case balance for gender, age and ward) randomly selected 120 cases for a sample of 447 patients at Rampton 1995-1998, 72 (16\%) of which were 
women. We examined the notes consecutively over 3 years, which resulted in 360 records. These were examined for documentation of the annual physical health check.

Results showed that 302 (84\%) had recorded evidence of the annual physical, and 11 patients (3\%) had declined examination. Few clinically significant abnormalities were detected (6 of $360,1.7 \%$ ), though these included cases of previously undiagnosed asthma, diabetes and anaemia. Wider review indicated that physical disease management was variable and non-systematic

We concluded that the traditional annual physical health check is of limited value. We felt that psychiatrists should review their current care and consider systematic primary care based services for long-term psychiatric in-patients and those on long-term follow-up.

SANTHOUSE, A. \& HOLLOWAY, F. (1999) Physical health of patients in continuing care. Advances in PsychiatricTreatment, 5, 455-462.

SMITH, R. (1999) Prisoners: an end to second class health care? British Medical Journal, 318, 954-955.

Graham Ness Clinical Lecturer in Forensic Psychiatry, Division of Forensic Psychiatry, ScHARR, Regent Court, 30 Regent Street, Sheffield S1 4DA

\section{Trainee access to computers}

Sir: Kotak \& Butler (Psychiatric Bulletin, January 2001, 25, 31-32) report the continued poor access to, and training in the use of, computers for junior psychiatrists. I have been fortunate throughout my specialist registrar training thus far to have had full internet access at both my place of clinical work and the university allied to it. Recently, on commencing an MSc I have been struck by the exceptional quality of computing services available to students. Unrestricted internet access, an effective system of e-mail communication and a profusion of terminals seems the norm and more youthful postgraduates than myself appear to expect no less. In the preparation of essays (in criminology and criminal justice, in my case) websites are listed in course guidebooks and the more enterprising students search the web for pre-written examples of essays!

An ability to access information to at least the standard of that experienced by students must surely be mandatory for today's doctors. Unfortunately, even where access to computers is provided, the level of access can vary. Some sites forbid internet access or restrict its use to pre-determined intranet sites. Focusing attention towards academia is laudable, but must surely at least permit the checking of one's e-mail. If a myriad of students can be trusted with such a facility it seems strange that some doctors are not.

Adrian R Brown Specialist Registrar in Forensic Psychiatry, Rampton Hospital, Retford, Nottingham DN22 OPD

Sir: Kotak \& Butler (Psychiatric Bulletin, January 2001, 25, 31-32) highlighted the importance of computers for psychiatrists in training. We share their disappointment that half of senior house officers and three-quarters of specialist registrars described having access to computers, and that, of these only one-quarter had internet access.

We have recently conducted a survey of psychiatric trainee attitudes in the Eastern region of the Republic of Ireland $(n=153)$ in which we found that only $67 \%$ of respondents ever used a computer at work. Access in the workplace to the internet is higher than in the London sample (54\%), but this figure and associated e-mail availability (29\%) appear disappointingly low.

The College recognises the importance of trainee involvement in research (Psychiatric Bulletin 1994, 18, 514-524), an area where computer access and skills are now essential. Perhaps it is not surprising that we found that those trainees in our sample who had access to a computer or to the internet at work were more likely to be actively involved in research. Kotak \& Butler have reported a demand among junior doctors for greater access to computers and the College recommends facilities for 'hands on' computerised literature searching for all trainees (Psychiatric Bulletin, 1994, 18, 514-524). Access is only half the point, in our sample only $71 \%$ of respondents rated their computer literacy as 'fair' or better: given the perceived demand and obvious potential benefits, should education in psychiatry include information technology training?

Aiden Corvin WellcomeTrust Research Fellow in Mental Health; e-mail: acorvin@tcd.ie, Edmond O'Mahony Health Research Board Clinical Research Training Fellow, Department of Psychiatry, Trinity Centre for Health Sciences, St James's Hospital, Dublin 8; e-mail: omahonep@ @tcd.ie

\section{the college}

\section{Comment on the following Joint Statement}

We are pleased to share with you the Joint Statement agreed between the Royal College of Psychiatrists and the Association of Chief Officers of Probation (ACOP).

Within the public policy areas of mental health, community safety and criminal justice, both organisations share issues of common interest.

The purpose of the joint statement is to promote engagement at a national level between the ACOP and the College in a form that stimulates and supports joint working between psychiatric and probation practitioners and managers at a local level.

The Government is seeking to achieve greater working across departmental boundaries, and collaboration between the ACOP and the College will contribute to this.
The Joint Statement is the product of an ACOP/RCPsych Liaison Group. Our sincere thanks are owed to the following members of the group who have informed and advised on the content: Dr Ranjit Baruah; Professor John Gunn; Dr Peter Snowden and Stuart McPhillips, ACOP Policy Development Advisor.

We will continue to work on the agenda identified in the Joint Statement and hope that it will be taken forward by the National Probation Service Directorate with the Royal College of Psychiatrists from April 2001.

If there are areas of work in the Joint Statement that you would like to discuss further please contact either the ACOP or the Royal College of Psychiatrists. We would be pleased to hear from you.

Mike Shooter Registrar, Royal College of Psychiatrists, Kathy Vagg Association of Chief Officers of Probation, Lead Officer, Health and Crime

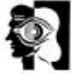

columns

\section{Joint Statement of Purpose by the Association of Chief Officers of Probation and the Royal College of Psychiatrists}

The Association of Chief Officers (ACOP) of Probation exists to:

- develop good practice and effective responses to crime, and to ensure the protection of children's welfare in cases of family separation

- consult and negotiate with Government departments on behalf of local probation services

- establish and maintain links with other organisations and bodies working in criminal justice and family court welfare

- encourage cooperative and collaborative endeavours between services in order to improve service delivery and achieve value for money

- promote equal opportunities. 